\title{
Why Hepatocellular Carcinoma (hcc)'s Management and Control is Challenging in the Developing Countries? Problems vs. Strategies
}

\section{Saleha Resham*}

Atta Ur Rahman School of Applied Biosciences (ASAB), National University of Science and Technology, NUST H-12 Islamabad, Pakistan

\section{Introduction}

Hepatocellular carcinoma (HCC) is a global health problem, although developing countries are disproportionally affected: over $80 \%$ of HCCs occur in such regions. Surprisingly about three-quarters of HCCs are attributed to chronic HBV and HCV infections. In areas endemic for HCV and HBV, viral transmission occurs at an early age, and unfortunately the infected individuals develop HCC in midadulthood. Reducing the life expectancy [1]. HCC is the 5th most common cancer in the world [2]. Among the major concerns; HCC prognosis is poor and is mostly diagnosed at an advanced stage [2].The number of patients is rising exponentially with each passing day. HCC is a concern that needs immediate attention [3].About 185 million people are living with $\mathrm{HCV}$, of which estimated $80 \%$ are living in low income and middle-income countries (LMICs) [4]. HCV infection that remains untreated leads to liver cirrhosis in up to two thirds of those who are chronically infected and these individuals are at risk for developing complications such as HCC and hepatic decompensation [5].

Since HCC is a disease with a very poor prognosis due to following reasons: resistance to conventional chemotherapy and limited efficacy of most potentially curative therapies [2]. Previous studies showed that, simultaneous infections with HBV and HCV have been postulated to accelerate the clinical progression of chronic hepatitis to cirrhosis and HCC [6]. Refer to Figure 1 showing the stages of liver damage below:

The global hepatitis burden has remained underestimated [7]. The mortality due to hepatitis B and C associated liver cancer account for $80 \%$ of viral hepatitis mortality burden.

Up to 500,000 people die each year from complications secondary to HCV infection; most in LMICs [8]. In general, the prognosis of most patients with HCC is poor due to the advanced stage at presentation and rapid clinical deterioration [9]. Despite the significant burden placed on communities across all global regions, hepatitis has been ignored largely as a health and development priority until recently. WHO has provided its first global health sector strategy on viral hepatitis, a strategy that contributes to the achievement of the "2030 Agenda for Sustainable Development". It covers the first six years of the post- 2015 health agenda, 2016-2021, building on the Prevention and Control of Viral Hepatitis Infection: Framework for Global Action, and on two resolutions on viral hepatitis adopted by the World Health Assembly in 2010 and in 2014 (http://www.who.int/reproductivehealth/ghsstrategies/en/).

There are associated the number of factors that make the management and control of this lethal life threatening complication, a serious health concern. Here are summed up both the problems and the strategies that should be immediately taken into practice to avoid them.

\section{Dilemmas Associated with HCC Management and Control}

The dilemmas of managing this disease are mentioned as follows:
(1) there are no proper reporting of statistical data of the infected HCC population. Neither the physicians nor the hospital technical/ clerical staff of diagnostic labs manage the wealth of information and data of the patients; making the healthcare scientist to find difficulty in collecting and reporting the data from a region. The exact number of HCC induced deaths annually is found missing. (2) There is no easy access to affordable treatment options for the patients who cannot afford the heavy treatment cost of the treatment. Moreover HCC prevalence is very difficult to mention from Asian countries. (3) Lack of knowledge and awareness about HCV are observed among healthcare providers, policy makers, the general public, and at risk populations. Forty percent of global HCV infections are due to unsafe injections and improperly sterilized medical equipment [10]. (4) Poor prognosis of hepatocellular carcinoma (HCC) is one of the major leading factors that has made HCC management challenging.

\section{Control and Management Strategies}

(1) There is a need for the proper training of the Health care providers. They need education and training to reduce the risk of disease transmission due to human error and malpractice.

(2) There is lack of sufficient understanding about the seriousness of this public health problem, so inadequate public resources are allocated for the prevention and control of HCV infection. There is a need to develop a global strategy for eradication of HCV.

More than 10 million people are on their feet due to the global polio eradication initiative, and the global incidence of polio has been reduced by $99 \%$ [11].

(3) To control the HCV pandemic at the massive level, it require the financial investment with the government's support along with support from the medical sector, civil sector (NGO's) and pharmaceutical industry around the globe.

The clinical implication if the distinctive proper attention is not given to the management of HCV and HCC, it has been reported that 20 million deaths will occur by hepatitis B only from 2015-2030 (WHO-global health strategy for viral hepatitis 2016-2020). Awareness campaigns need to plan to decrease the future burden of HCV on the society. However what are the obstacles hindering in managing this life threatening illness? There are so many challenges to overcome for a

*Corresponding author: Saleha Resham , Atta Ur Rahman School of Applied Biosciences (ASAB), National University of Science and Technology, NUST H-12 Islamabad, Pakistan, Tel: +92334-0011992; E-mail: saleha.resham04@gmail.com

Received January 05, 2016; Accepted February 03, 2016; Published February 20, 2016

Citation: Resham S (2016) Why Hepatocellular Carcinoma (hcc)'s Management and Control is Challenging in the Developing Countries? Problems vs. Strategies. $\mathrm{J}$ Integr Oncol S1: 005. doi:10.4172/2329-6771.S1-005

Copyright: @ 2016 Resham S. This is an open-access article distributed unde the terms of the Creative Commons Attribution License, which permits unrestricted use, distribution, and reproduction in any medium, provided the original author and source are credited. 
Citation: Resham S (2016) Why Hepatocellular Carcinoma (hcc)'s Management and Control is Challenging in the Developing Countries? Problems vs. Strategies. J Integr Oncol S1: 005. doi:10.4172/2329-6771.S1-005

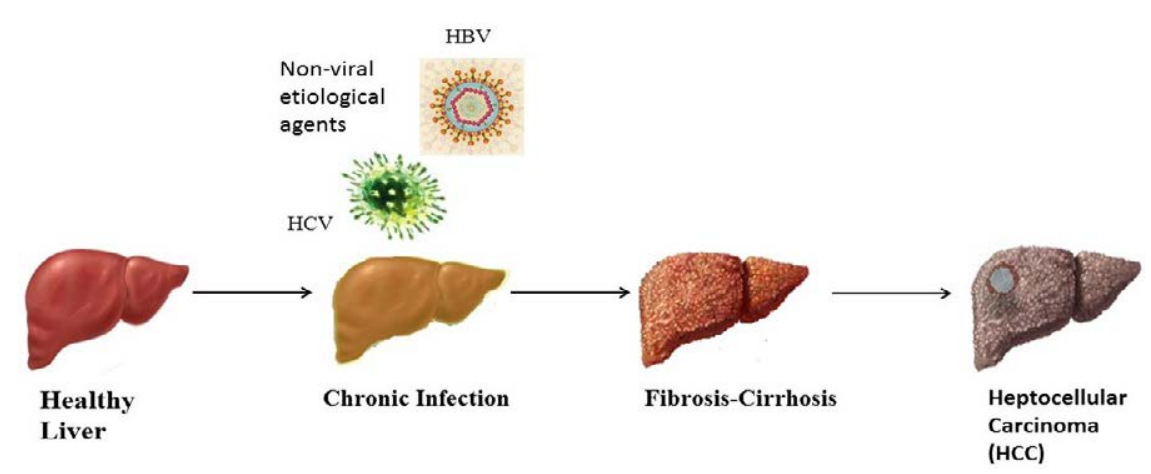

Figure 1: Stages of liver damage (HCC development). The healthy liver will shift to fibrosis and cirrhosis upon getting infected with either a viral agent or a non-viral agent that leads to the HCC development if not treated and diagnosed early.

developing countries like Pakistan and India. A lot more struggle needs to be concentrated upon overcoming these challenges together with the government and international support. Because the prevalence of the disease is getting at an alarming level. And there is an urgent need for emergency planning for the disease management at the national levels.

\section{References}

1. Yang JD, Roberts LR (2010) Hepatocellular carcinoma: A global view. Nat Rev Gastroenterol Hepatol 7 : 448-458.

2. Debruyne EN, Delanghe JR (2008) Diagnosing and monitoring hepatocellular carcinoma with alpha-fetoprotein: new aspects and applications. Clinica Chimica Acta 395: 19-26.

3. Saalim M, Resham S, Manzoor S, Ahmad H, Jaleel S, et al. (2015) IL-22: a promising candidate to inhibit viral-induced liver disease progression and hepatocellular carcinoma. Tumour Biol.

4. Wedemeyer H, Duberg AS, Buti M, Rosenberg WM, Frankova S, et al. (2014) Strategies to manage hepatitis $\mathrm{C}$ virus (HCV) disease burden. J Viral Hepat 21 Suppl 1: 60-89.

5. Davis GL, Alter MJ, El-Serag H, Poynard T, Jennings LW (2010) Aging of hepatitis $\mathrm{C}$ virus ( $\mathrm{HCV}$ )-infected persons in the United States: a multiple cohort model of HCV prevalence and disease progression. Gastroenterology 138 : 513-521.

6. Yu MC, Tong MJ, Coursaget P, Ross RK, Govindarajan S, et al. (1990) Prevalence of hepatitis B and $C$ viral markers in black and white patients with hepatocellular carcinoma in the United States. J Natl Cancer Inst 82: 10381041.

7. Waheed $Y$ (2015) Hepatitis C eradication: A long way to go. World J Gastroenterol 21: 12510-12512.

8. Lozano R, Naghavi M, Foreman K, Lim S, Shibuya K, et al. (2012) Global and regional mortality from 235 causes of death for 20 age groups in 1990 and 2010: a systematic analysis for the Global Burden of Disease Study 2010. Lancet 380: 2095-2128.

9. Okuda K, Ohtsuki T, Obata H, Tomimatsu M, Okazaki N, et al. (1985) Natura history of hepatocellular carcinoma and prognosis in relation to treatment. Study of 850 patients. Cancer 56: 918-928.

10. Averhoff FM, Glass N, Holtzman D (2012) Global burden of hepatitis C: considerations for healthcare providers in the United States. Clin Infect Dis 55 Suppl 1: S10-15.

11. Aylward B, Tangermann R (2011) The global polio eradication initiative: lessons learned and prospects for success. Vaccine 29 Suppl 4: D80-85.

This article was originally published in a special issue, Oncology and

Biophysics: A Need for Integration handled by Editor(s). Dr. Sarah S Knox, West Virgnia University 